\title{
MOVILIDAD FORZADA POR LAS DINÁMICAS DEL NARCOTRÁFICO: VARIABLES PARA EL ANÁLISIS DEL PROCESO DE ASILO DE MEXICANOS POR VIOLENCIA EN EE.UU.
}

Estefanía Cruz Lera

\author{
LA VIOLENCIA POR NARCOTRÁFICO Y LA GENERACIÓN \\ PROGRESIVA DE NUEVOS REFUGIADOS COMO DESFOGUE \\ DEL SISTEMA CAPITALISTA
}

El propósito de este apartado consiste en explicar breve y acotadamente cómo las migraciones forzadas por violencia derivada del narcotráfico son parte de una compleja espiral de problemáticas que resultan de un subsistema (mercado de sustancias ilícitas), que se genera por la coincidencia de la demanda y el paradigma prohibicionista en las áreas centro y cuyas consecuencias más nocivas exporta a las periferias. ${ }^{1}$

El capitalismo como sistema mundial en el que vivimos inmersos abandera como sus valores fundamentales las libertades y el individualismo, a más de prometer que a partir del libre intercambio de capitales los imaginarios colectivos podrán desarrollarse y

${ }^{1}$ Se retoma el acercamiento analítico de los sistemas-mundo, que sostiene que un sistema es una entidad cuyas partes y relaciones se caracterizan por una alta sinergia. En este caso, el sistema mundial capitalista es un sistema abierto, compuesto de varios subsistemas, es decir estructuras con dinámicas propias que lo conforman y que también se extienden desigualmente entre áreas centro y periferia. Para ahondar más en esta aproximación metodológica, véanse dos trabajos de I. Wallerstein: Análisis de sistemas-mundo. Una introducción, México, Siglo XXI, 2005, y "A world-system perspective on the social sciences", en The capitalist worldeconomy, Cambridge, University Press, 1979, pp. 152-164 (publicado por primera vez en 1976 en British Journal of Sociology, vol. 27, núm. 3, pp. 343-352). 
alcanzar "el progreso económico". Esta derrama cubriría paulatinamente las demandas sociales y culturales y haría menos necesario el gobierno, cuya tarea se reduciría a la impartición de justicia y a otras cuestiones administrativas. Sin embargo, sus beneficios y efectos no se han distribuido equitativamente en el planeta.

Tanto en las áreas centro como en la periferia, se han generado subsistemas con un carácter intrínseco productor de outputs ${ }^{2}$ negativos, degradantes y destructores, y crisis que en vez de solucionarse se vierten como desechos en los grupos sociales más vulnerables. ${ }^{3}$ Como consecuencia se crea una subeconomía a partir de la doble moralidad del capitalismo, derivada de la penalización de actividades rezagadas a lo ilícito que, sin embargo, por la presión y la deshumanización que en muchos espacios sufre el estilo de vida contemporáneo tienen un amplio mercado negro.

Entre estos subsistemas se encuentra el narcotráfico -y las dinámicas que lo componen en el proceso de producción, distribución y consumo-, que genera círculos viciosos de muerte, violencia, corrupción, además de vejaciones a los derechos y libertades fundamentales y, por tanto, una vasta movilidad humana forzada al interior y al exterior de las fronteras internacionales. El tráfico de sustancias psicotrópicas hace simbiosis con las actividades financieras establecidas - por medio, por ejemplo, del lavado de dinero-, y con la industria del entretenimiento, que propone modelos de éxito que normalizan el consumo de drogas. ${ }^{4}$

${ }^{2}$ En este modelo, los inputs más relevantes para el fenómeno estudiado pueden ser: la existencia de demanda y el paradigma prohibicionista, las políticas para tratar el problema como actividad ilícita y no como un problema sanitario versus garantías sociales y derechos humanos. Los outputs se refieren a las salidas o efectos de la interacción de estas contradicciones en el sistema, entre ellos la movilidad forzada que es el objeto de estudio central de este documento.

${ }^{3}$ Véase Z. Bauman, Vidas desperdiciadas. La modernidad y sus parias, Barcelona, Paidós, 2005, pp. 85-93.

${ }^{4}$ S. Valencia (Capitalismo Gore, Barcelona, Melusina, 2010) explica cómo estas actividades deshumanizan: "Cuerpos concebidos como productos de intercambio que alteran y rompen las lógicas del proceso de producción del capital, ya que subvierten los términos de este al sacar del juego la fase de producción de la mercancía, sustituyéndolo por una mercancía encarnada literalmente en el cuerpo y la vida humana, a través de técnicas predatorias de violencia extrema”. 
Slavoj Žižek explica que una consecuencia innata y catastrófica del funcionamiento del sistema es la violencia en sus variantes objetiva y subjetiva:

la violencia subjetiva se experimenta como tal, en contraste con un fondo de nivel cero de violencia. Se ve como una perturbación del estado de las cosas "normal" y pacífico. Sin embargo, la violencia objetiva es precisamente la violencia inherente a este estado de cosas "normal". La violencia objetiva es invisible, puesto que sostiene la normalidad de un nivel cero contra lo que percibimos como subjetivamente violento. ${ }^{5}$

En este sentido, las sociedades minimizan fenómenos por ser de distinta naturaleza de las notas rojas o de catástrofes que acontecen en otros espacios de guerra abierta y con esto "normalizan" las condiciones violentas de su existencia. Ocurre lo anterior sin notar que sus dinámicas de convivencia y consumo inefablemente están insertas en una espiral de violencia cuyos efectos negativos descarga cerca y lejos de su espacio cotidiano. ${ }^{6}$

El narcotráfico se convierte entonces en un complejo problema estructural por la existencia de una demanda global y la existencia de una producción local. También es un fenómeno superestructural por el marco de ilegalidad que se genera, que además se agudiza al imbricarse con las fuerzas coercitivas del Estado, como los servidores públicos, militares y policías, que voluntariamente o bajo amenaza participan en esa cadena "glocal" que ya ha ocupado todo el planeta. Los grandes carteles funcionan como corporaciones que siguen la lógica lucrativa de otras empresas transnacionales, ${ }^{7}$ con la salvedad de que en su voracidad generan violencia desencadenada. ${ }^{8}$

5 "Sobre la violencia. Seis reflexiones marginales", trad. de A. J. Antón Fernández, Buenos Aires, Paidós, 2009, p. 20.

${ }^{6}$ Bauman, op. cit.

${ }^{7}$ P. Reuter, "On the Multiple Sources of Violence in Drug Markets", Criminology E゚ Public Policy, vol. 15, núm. 3, 2016, pp. 877-883.

${ }^{8}$ L. Astorga, Drogas sin fronteras, México, Debolsillo, 2015, p. 378. 
La corporación se divide en ramas como la producción, la distribución, el sicariato, el lavado de dinero y otros sectores especializados y cuyas estrategias de mercado ven como un costo menor las muertes, las desapariciones forzadas y los desplazados. Bezares lo explica de este modo:

El rostro más visible del narcotráfico es la violencia, hoy protagonista del noticiero nacional, pero su maquinaria es más vasta y compleja de lo que suele imaginarse; el narco es dinero [...], poder puro y duro, poder que se ejerce y que moviliza, enemigo de la teoría y de la abstracción; el narco es una red de relaciones humanas tan grande y extendida [...]; el narco es cultura e idiosincrasia, ha permeado en la psique del mexicano hasta la costumbre; vivimos con él, con sus íconos de sangre y oro, con su jerga, todo a ritmo de corrido. ${ }^{9}$

Al margen, aparecen diversos fenómenos sociales derivados de la violencia como las desapariciones obligadas, los desplazamientos internos, las migraciones forzadas y los refugiados internacionales. Las personas escapan del desfogue de los desechos del capitalismo, que Monsiváis resume de este modo: "La siembra de mariguana y amapola, de ningún modo reciente, ha sido desde la década de 1980 fuente sistemática de perturbación, incursiones punitivas de los judiciales y del ejército, asesinatos a mansalva, torturas, saqueos, desapariciones, violaciones". ${ }^{10}$ Ésa es precisamente la vida cotidiana de ciudades y pueblos que tuvieron la desventura de coincidir geográfica o políticamente con las redes de producción y distribución del narcotráfico, que a causa también de otras problemáticas como los cacicazgos, el desempleo y la pobreza, se volvieron consumidores. Regiones enteras se convirtieron en plazas y enclaves del narco, donde éste subyugó a las poblaciones y sus dinámicas sociales, apoderándose de gobiernos locales para que participaran y

${ }^{9} \mathrm{H}$. Bezares Buenrostro, Análisis sobre los fundamentos políticos de las políticas antinarcóticos en los Estados Unidos, tesis, México, Universidad Nacional Autónoma de México, 2007, p. 147.

10 "El narcotráfico y sus legiones", en C. Monsiváis et al., Viento rojo. Diez historias del narco en México, México, Plaza y Janés, 2004, p. 24. 
apoyaran sus actividades; ${ }^{11}$ es decir que el narcotráfico genera una cadena donde cada parte del proceso funciona como un engrane e incluso la violencia funge como desfogue de un sistema que no se detiene, que se sobresatura y ejerce presión sobre los imaginarios sociales. ${ }^{12}$ En sus momentos críticos, se convierte en el discurso de los gobiernos en un enemigo acérrimo de la seguridad nacional a pesar de que sólo es uno de los niveles más graves de la criminalidad neoliberal. ${ }^{13}$ La lucha contra el narcotráfico tiene al menos una batalla perdida, pues si hay mercado y si hay lucro, las víctimas se convierten sólo en efectos colaterales, ${ }^{14}$ mientras que los que sobreviven se convierten en desplazados internos y en casos más graves en refugiados internacionales.

En este punto, surge un cuestionamiento fundamental: qué fue lo que detonó la violencia según el grado que las estadísticas reflejan. Hay muchas variables por considerar: en primera instancia, el cambio en la distribución del poder entre carteles, la lucha por rutas y espacios, ${ }^{15}$ que se intensificó por la persecución gubernamental de estos grupos, los cuales ya se habían infiltrado en los aparatos estatales por medio de funcionarios públicos, policía y fuerzas armadas corruptas, para financiar más tarde a gobernadores y alcaldías.

Tras el estallido de la violencia generalizada, muchas comunidades en México se volvieron inhabitables; se convirtieron en escenarios de guerra y las violaciones a los derechos humanos se volvieron una problemática nacional:

La huida como mecanismo de defensa, el desarraigo como último y desesperado refugio de la violencia y de las extorsiones, los fuegos

${ }^{11}$ Astorga, op. cit.

12 Sayak, op. cit.

${ }^{13}$ Véase E. Buscaglia, Vacíos de poder en México. El camino de México hacia la seguridad humana, pról. de Carmen Aristegui, México, Debate, 2013.

${ }^{14}$ Las estadísticas reflejan los siguientes datos sobre el costo humano de la violencia entre 2006-2014: ejecuciones, 164000 (INEGi 2015); desaparecidos, 27659 (Secretaría de Gobernación México, 2013); desplazados, entre 280000 y 300000 (Movimiento por la paz con justicia y dignidad, 2015).

${ }^{15}$ Astorga, op. cit. 
cruzados, los secuestros y las amenazas han sido consecuencias de la guerra que han pasado casi completamente inadvertidas en México. En el país hay un número creciente de personas y, en ocasiones, de comunidades enteras que prefieren abandonar sus casas, tierras y negocios, a vivir la violencia. ${ }^{16}$

De este modo, se intensifican dos fenómenos que crecen hasta convertirse en crisis humanitarias invisibles: los desplazados internos y los refugiados internacionales a causa de la violencia provocada por el narcotráfico.

LOS REFUGIADOS Y DESPLAZADOS: CONSECUENCIAS DE DINÁMICAS GLOBALES CON EFECTOS Y RESPONSABILIDADES FOCALIZADAS

El propósito principal de este apartado es señalar cómo los migrantes forzados por violencia derivada del narcotráfico no encuadran en las categorías internacionales y norteamericanas sobre refugio y asilo. La categoría de "migrantes forzados" se refiere a todas aquellas personas que tuvieron que dejar sus hogares por cuestiones involuntarias, ajenas, abruptas e inesperadas, y que por las mismas circunstancias no pueden regresar:

La tendencia -dice Durin- es llamarlos a todos "refugiados", pero ésta es una categoría legal bastante restringida. La mayoría de los migrantes forzados huyen por razones que no son reconocidas por el régimen internacional de refugiados y muchos de ellos son desplazados dentro de su propio país de origen. ${ }^{17}$

En este punto es necesario repasar los marcos de referencia internacionales sobre refugiados que rigen en Norteamérica. En primera

16 S. Albuja y L. Rubio Díaz-Leal, "Los olvidados de la guerra contra el narcotráfico en México. Los desplazados internos", Foreign affairs: Latinoamérica, vol. 11, núm. 4, 2014, pp. 23-31.

${ }^{17}$ S. Durin, "Los que la guerra desplazó: familias del noreste de México en el exilio”, Desacatos, núm. 38, enero-abril 2012, p. 30. 
instancia, la Convención sobre el Estatuto de los Refugiados establece que un refugiado es una persona que

debido a fundados temores de ser perseguida por motivos de raza, religión, nacionalidad, pertenencia a un determinado grupo social u opiniones políticas, se encuentre fuera del país de su nacionalidad y no pueda o, a causa de dichos temores, no quiera acogerse a la protección de su país. ${ }^{18}$

En esta definición, destacan los pilares fundamentales de temor fundado, persecución y los motivos enlistados que son universalmente aceptados para reconocer el estatuto de refugiado. Posteriormente, en el "Manual sobre criterios y procedimientos para determinar el estatus de refugiado", ${ }^{19}$ se amplían las definiciones, estableciendo que se considerarán persecución las acciones de amenaza a la vida o a la libertad, otras violaciones humanas serias, acciones perjudiciales y discriminación sustancialmente perjudicial, todo lo cual se caracteriza por la ausencia e ineficacia de protección estatal y la necesidad de protección internacional.

Las razones expuestas para el rechazo de solicitudes de asilo por narcotráfico son similares: los regímenes internacionales de refugiados no aplican a víctimas de la delincuencia organizada transnacional. La razón principal de esta laguna en las convenciones internacionales es que tanto el refugio como el asilo son figuras que corresponden a una perspectiva eurocentrista durante los periodos históricos de guerras mundiales. Al respecto, Zolberg, Suhrke y Aguayo argumentan que esta definición clásica preveía protección sólo para los perseguidos religiosos, opositores políticos, minorías étnicas y apátridas, pues fue concebida tras la Segunda Guerra Mundial para las principales víctimas de los regímenes fascistas

18 ACNUR, Convención sobre el Estatuto de los Refugiados, adoptada en Ginebra, Suiza, el 28 de julio de 1951, por la Conferencia de plenipotenciarios, en http:// www.acnur.org/fileadmin/scripts/doc.php?file=fileadmin/Documentos/BDL/ 2001/0005.

${ }^{19}$ ACNUR, Manual de procedimientos y criterios para determinar la condición de refugiado en virtud de La Convención de 1951 y el Protocolo de 1967 sobre el Estatuto de Los Refugiados, en http://www.acnur.org/t3/fileadmin/Documentos/BDL/2011/75 75.pdf 
y los genocidios de la primera mitad del siglo xx. ${ }^{20}$ En esa coyuntura, los estados o grupos políticos al interior del Estado (golpistas, paramilitares, guerrillas, regímenes autoritarios, etc.) eran los únicos que podrían amenazar a minorías étnicas o ideológicas. En ningún caso se contempló la aparición de grupos como mafias y terroristas, que son los principales generadores de violencia que motivan olas de refugiados contemporáneos en el mundo.

Esta ambigüedad en el derecho internacional vuelve discrecionales y casuísticas las solicitudes de asilo y refugio por parte de los desplazados internacionales a causa del narcotráfico. La violencia por el narcotráfico, la incapacidad del Estado para garantizar los derechos y libertades fundamentales, la corrupción y la impunidad procedente de un sistema de justicia con problemas estructurales provocan que grupos vulnerables vivan el miedo, el hostigamiento, las amenazas, la persecución, el secuestro, las agresiones y asesinatos de sus seres queridos. En este sentido, las víctimas del narcotráfico podrían calificar los criterios subjetivos y objetivos (pudiendo sustentarse la racionalidad y plausibilidad de los hechos) de temor fundado y persecución. Sin embargo, hay varias limitantes; además de los criterios de "persecución, temor fundado y plausibilidad", las solicitudes incumplen también los parámetros sobre los perpetradores. ACNUR reconoce como "ejecutores" a gobiernos nacionales, locales, milicias y casos de violencia doméstica, pero los carteles de narcotraficantes no encajan con estos ejecutores tradicionales. ${ }^{21}$

Aunado a los criterios definitorios y procedimentales previamente analizados, también en la parte subjetiva del proceso parece haber poca comprensión sobre las migraciones forzadas por violencia derivada del narcotráfico. Los oficiales calificadores y los jueces de plaza $^{22}$ que rechazan las solicitudes impugnan que la

${ }^{20}$ Escape from Violence: Conflict and the Refugee Crisis in the Developing World, Oxford, University Press, 1989.

${ }^{21}$ Véase E. Barry-Murphy y M. Stephenson Jr., "Recognizing and Confronting State Subjectivity in Asylum Adjudications", Refuge, vol. 31, núm. 2, 2015, pp. 1-17.

${ }^{22}$ Una vez registrada la solicitud de asilo, se requiere una evaluación, o entrevista, en la cual un oficial calificador determine su elegibilidad. En caso afirmativo, se procederá a un juicio en que el juez de plaza decidirá si otorga el estatus. Ésta constituye la parte subjetiva del proceso. 
violencia en México no es generalizada, que se pueden reubicar en otra parte del territorio nacional. Además, argumentan que hay voluntad política del gobierno mexicano para combatir al narcotráfico (aunque esta "guerra" genera a su vez más violencia) e impugnan que hay cooperación internacional mediante la Iniciativa Mérida. En general, presentar un caso sólido y argumentado es una tarea difícil para las víctimas de violencia. ${ }^{23}$

S. Albuja apunta que los refugiados por violencia del narcotráfico se han valido de legislaciones internacionales complementarias, como la Convención contra la tortura y la Convención para la protección de todas las personas contra la desaparición forzada. ${ }^{24}$ Ambas prohíben la repatriación de personas a un estado donde corran el riesgo de desaparecer. Sin embargo, el panorama es desolador, pues no es simplemente dejar atrás lo conocido y el patrimonio. Después del peligroso viaje a la frontera, inicia un largo e incierto juicio. Los casos de solicitantes de asilo son diversos: hay comerciantes, agricultores, periodistas, activistas, prensa, policías, funcionarios públicos. Sorprenden las historias de personas que accidentalmente son confundidas con integrantes de carteles, que son amedrentados, perseguidos y pierden a sus familias hasta que no hay otra alternativa que escapar al extranjero. ${ }^{25}$ La violación sistemática de derechos humanos refleja estructuras gubernamentales en crisis.

Un caso representativo presenta Balderas en su investigación periodística en la que describe cómo las veintidós familias del poblado de Santa María Sur (ubicado en la violenta región de Tierra Caliente, Guerrero, en el llamado "pentágono de la amapola") tuvieron que ubicarse en un hotel de la capital provincial, porque el territorio está en disputa entre tres grupos de narcotraficantes que luchan entre ellos por la plaza, más el ejército y la policía estatal. ${ }^{26}$

${ }^{23}$ S. Albuja, "Criminal violence and displacement in Mexico", Forced Migration Review, núm. 45, 2014, pp. 28-31.

${ }^{24}$ Idem.

${ }^{25}$ Cf. D. Uchimiya, "Falling Through the Cracks: Gang Victims As Casualties in Current Asylum Jurisprudence”, Berkeley La Raza Law Journal, vol. 23, 2013, pp. 109-162.

${ }^{26}$ Ó. Balderas, "El hotel donde vive un pueblo entero desplazado por el narcotráfico", Vice News, 15 de marzo de 2016. 
Sin embargo, este caso corresponde a los 280000 desplazados internos ${ }^{27}$ que ha causado la guerra fallida contra el narcotráfico en México, pero hay otros casos en que las personas afectadas tienen que traspasar fronteras internacionales para escapar de la violencia y salvar sus vidas.

Cabe destacar que contabilizar la movilidad forzada por violencia derivada del narcotráfico implica muchos desafíos metodológicos. En primera instancia, las estadísticas no son del todo confiables, ya que muchos casos se contabilizan en el flujo mixto de migrantes mexicanos a Estados Unidos. ${ }^{28}$ Además, en Estados Unidos la información de los procesos judiciales se desclasifica con posterioridad, y dada la diferente naturaleza de los casos, no se centraliza.

Las migraciones forzadas internacionales por violencia se pueden apreciar con mayor frecuencia en las franjas fronterizas, porque el proceso generalmente obliga al solicitante a alcanzar algún puerto de entrada del país al que se pretende aplicar y, por tanto, es en las ciudades de la frontera México-Estados Unidos donde más se presentan las solicitudes de asilo. ${ }^{29}$ Uno de los casos más explorados es el movimiento poblacional entre Ciudad Juárez (Chihuahua, México) y El Paso (Texas, Estados Unidos), donde se estima que 125000 personas se han refugiado del lado norte de la frontera escapando de la violencia. Los tribunales están actualmente abrumados con casos de asilo: en El Paso, por ejemplo, está tomando aproximadamente tres años que los solicitantes obtengan una cita en las cortes. ${ }^{30}$ Este movimiento se ha dado bajo las sombras de las dinámicas de una ciudad fronteriza, pues muchos de los refugiados son de clase media y alta

27 IDMC, "Global Report on Internal Displacement", 2016, en http://www.internal-displacement.org/assets/publications/2016/2016-global-report-internaldisplacement-IDMC.pdf

${ }^{28}$ D. Boehm, "US-Mexico Mixed Migration in an Age of Deportation: An Inquiry into the Transnational Circulation of Violence”, Refugee Survey Quarterly, vol. 30, núm. 1, 2011, pp. 1-21.

${ }^{29}$ M. Morales et al., "The Mexican Drug War and the Consequent Population Exodus: Transnational Movement at the U.S.-Mexican Border", Societies, vol. 3, núm. 1, 2013, pp. 80-103.

${ }^{30} \mathrm{Id}$. 
que utilizan la doble nacionalidad, visas de turista, visas de inversores y trabajo para huir de la violencia, lo que hace más difícil contabilizarlos. $^{31}$

\section{LOS REFUgIAdos MEXicanos EN Estados Unidos}

El principal propósito de este apartado es exponer las características de los mexicanos solicitantes de asilo en Estados Unidos y explicar los obstáculos a los que se enfrentan para que se los defina como grupo de riesgo y candidatos a individuos con necesidad de protección internacional.

En el derecho estadounidense no hay diferencias entre asilo y refugio ${ }^{32}$ y, por tanto, cada caso se atiende individualmente, lo cual establece jurisprudencia que, además de los tratados internacionales adscritos, es la única referencia para apoyar los procesos. Aunado a esto, los refugiados por violencia del narcotráfico o el crimen organizado no son perfectamente ubicados como grupo de riesgo ni por el derecho internacional, ni en Estados Unidos. ${ }^{33}$ Por tanto, los mecanismos y legislaciones sobre protección internacional e intervención humanitaria muchas veces son inaplicables. Por ejemplo, el fragile states index otorga a México una calificación de 70.4 ( high warning), y uno de los componentes de este índice es el de refugiados, en el que el país obtiene un 4.1 (moderate) ${ }^{34}$ Sin embargo, estas estadísticas no deben leerse a la ligera, pues miden el flujo de refugiados, es decir solicitantes de asilo en México menos solicitantes mexicanos de asilo, y nuestro

31 J. C. Martínez et al., "Unrelenting Violence and Lawlessness Forces Thousands of Middle-Class Mexicans to Relocate Seeking Safety in the U.S. and in More Peaceful Regions in México”, Mexodus, 31 de junio de 2011.

${ }^{32}$ A. Estévez, "Asilo y derechos humanos en Estados Unidos y Canadá. Cuestionamientos a Giorgio Agamben”, Norteamérica, vol. 7, núm. 1, 2012, pp. 183-206.

33 S. Campos y J. Friedland, "Mexican and Central American Asylum and Credible Fear Claims: Background and Context", American Immigration Council, 21 de mayo de 2014.

34 The Fund for Peace, "Fragile States Index", 2016, en http://fsi.fundforpea ce.org/ 
país recibe grandes flujos de Centro y Sudamérica, el Caribe e incluso África. ${ }^{35}$

Sobre los flujos de mexicanos en busca de protección internacional atendidos por el Alto comisionado de Naciones Unidas para los refugiados, el organismo reporta las siguientes cifras para Norteamérica:

\section{Cuadro 1}

Buscadores de asilo mexicanos en Norteamérica

\begin{tabular}{crc}
\hline Año & EE.UU. & Canadá \\
\hline 2000 & 12372 & 1967 \\
2001 & 21289 & 2769 \\
2002 & 28522 & 4000 \\
2003 & 23708 & 4386 \\
2004 & 15856 & 4707 \\
2005 & 9937 & 4981 \\
2006 & 7934 & 7149 \\
2007 & 7596 & 12524 \\
2008 & 7999 & 15415 \\
2009 & 7856 & 18873 \\
2010 & 2074 & 14603 \\
2011 & 3140 & 9571 \\
2012 & 4521 & 7367 \\
2013 & 14552 & 6962 \\
2014 & 33062 & 6778 \\
2015 & 50879 & 6471 \\
\hline
\end{tabular}

Fuente: elaboración propia con Base de datos online de estadísticas de población de ACNUR, disponible en http:/ / popstats.unhcr.org/

Sin embargo, no todos los registrados por ACNUR acceden a procedimiento. Aun así, en 2013 los mexicanos fueron el segundo grupo nacional con más solicitudes de asilo en Estados Unidos, sólo detrás

${ }^{35}$ Según ACNUR, en 2015 se recibieron 17782 personas en situación de necesidad de protección internacional. Véase S. Cobo y P. Fuerte, "Refugiados en México. Perfiles sociodemográficos e integración social", ACNUR México, en http:// www.acnur.org/t3/fileadmin/Documentos/Publicaciones/2013/9167.pdf 
de China. ${ }^{36}$ Entre 2006-2015, el Departamento de Justicia de Estados Unidos recibió 65202 solicitudes de asilo. ${ }^{37}$ La tendencia se puede observar mejor tanto en el cuadro 2, como en la gráfica 1:

\section{Cuadro 2}

Solicitudes de asilo de mexicanos presentadas en EE.UU.

\begin{tabular}{ccccc}
\hline Año & Solicitudes & Aprobadas & Rechazadas & Abandonadas \\
\hline 2006 & 2611 & 48 & 297 & 2266 \\
2007 & 3133 & 49 & 288 & 2796 \\
2008 & 3630 & 73 & 249 & 3308 \\
2009 & 3698 & 65 & 364 & 3269 \\
2010 & 4510 & 49 & 382 & 4079 \\
2011 & 7454 & 92 & 1010 & 6352 \\
2012 & 10920 & 113 & 1036 & 9771 \\
2013 & 10177 & 155 & 1576 & 8446 \\
2014 & 10143 & 124 & 1854 & 8165 \\
2015 & 8926 & 203 & 1764 & 6959 \\
\hline
\end{tabular}

Fuente: elaboración propia con datos del U. S. Department of Justice, art. cit., y de M. Morales et al., art. cit.

Por restricciones del Congreso estadounidense, ésta es la única información que se puede obtener. Las razones individuales y las características de los casos se mantienen en privado. ${ }^{38}$ Pero, en general, los autores coinciden en que el incremento de peticiones provenientes de México se debe a la violencia resultante de una combinación entre grupos de narcotráfico y actores gubernamentales, caracterizada por la impunidad judicial. ${ }^{39}$

${ }^{36}$ J. A. Cabot, "Problems Faced by Mexican Asylum Seekers in the United States", Journal on Migration and Human Security, vol. 2, núm. 4, 2014, pp. 361-377.

${ }^{37}$ U. S. Department of Justice, "Asylum Statistics", 2016, en https:/ /www.justice.gov/eoir/file/asylum-statistics/download

${ }^{38}$ L. Camp Keith y J. S. Holmes, "A Rare Examination of Typically Unobservable Factors in US Asylum Decisions”, Journal of Refugee Studies, vol. 22, núm. 2, 2009, pp. 224-241.

${ }^{39}$ Campos y Friedland, art. cit. 
GRÁFICA 1

Solicitudes de asilo de mexicanos presentadas en EE.UU.

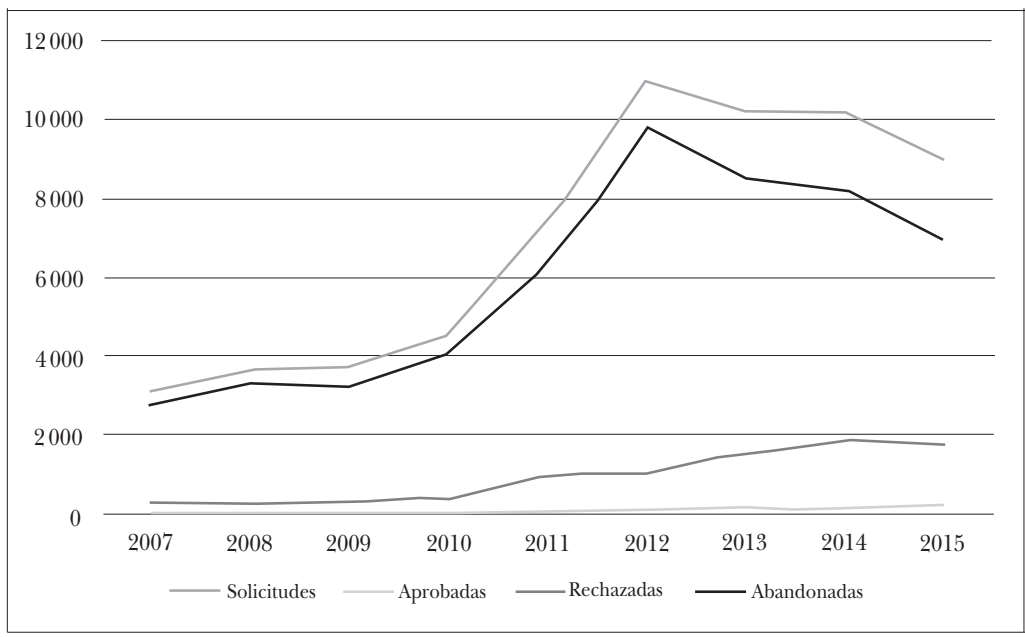

Fuente: elaboración propia con datos del U. S. Department of Justice, art. cit., y de M. Morales et al., art. cit.

Un claro problema de los refugiados por las dinámicas del narcotráfico, es que no son un grupo homogéneo o focalizado, a diferencia de los perseguidos por motivos étnicos, religiosos, o por oposición política. ${ }^{40}$ Los mexicanos sólo comparten la frustración y desgracia de una "guerra nueva", de interferir con cadenas productivas de demanda global, cuyo canal de escape es la violencia objetiva y subjetiva en México. Son personas provenientes de los "muchos Méxicos", del norte y del sur, de la costa y la montaña, de campos y ciudades, ricos y pobres, campesinos, empresarios y burócratas, entre quienes la ideología política, religiosa, étnica y otras características sociales que regularmente ayudan a definir un grupo de riesgo se vuelven una variable indiferente comparada con otros casos de asilo en el mundo. 
Una crítica importante es que en Estados Unidos, a la inversa de Latinoamérica, donde las figuras y los procedimientos están diferenciados, el refugio se concede como "asilo" y, por tanto, se convierte en un asunto político. Barry-Murphy, en su artículo citado, explica que la concesión de asilo en Estados Unidos siempre ha estado vinculada a la política exterior del país y, en consecuencia, a la seguridad nacional. En este sentido, Rosenblum argumenta, en su estudio comparativo de solicitudes de 42 países, que Estados Unidos tiende a rechazar solicitudes provenientes de naciones con las que tiene buenas relaciones diplomáticas, aun a pesar de que el ambiente de derechos humanos sea crítico, regularmente argumentando que hay condiciones de gobernabilidad y la situación se complica aún más si Estados Unidos coopera en esos lugares con recursos para el desarrollo o con fondos de asistencia para la paz. ${ }^{41}$

\section{EL PROCEDIMIENTO DE ASILO EN EE.UU.}

El propósito principal de esta sección es explicar en términos generales las vías que sigue el procedimiento de asilo en Estados Unidos, exponiendo las diferencias entre dos posibilidades, el asilo defensivo y el afirmativo, para entender cómo cada caso es particular y enunciar las razones de la poca certeza del proceso.

Aunque Estados Unidos no es miembro de la Convención de 1951, pero sí del protocolo de 1967 y del Alto Comisionado de Naciones Unidas para los refugiados, se utilizan como referencia las siguientes condiciones enlistadas en este tratado para aceptar una solicitud de asilo: $a$ ) estar fuera del país de origen; $b$ ) ser incapaz de retornar o de obtener protección de su país; $c$ ) temor bien fundado de persecución; $d$ ) pertenecer a un grupo de riesgo; $e$ ) pruebas fehacientes de la persecución (denuncias, testimonios y otras pruebas legales). ${ }^{42}$

41 "Norms and Interests in US Asylum Enforcement", Journal of Peace Research, vol. 41, núm. 6, 2016, pp. 677-697.

${ }^{42}$ H. Buchanan, "Fleeing the Drug War Next Door: Drug-Related Violence as a Basis for Refugee Protection for Mexican Asylum-Seekers", Merkourios, vol. 27, núm. 72, 2011, pp. 28-60, en http://www.merkourios.org/index.php/mj/article/view/21 
Si bien estos marcos de referencia internacionales sirven como guías y referencias en el proceso, la tradición jurídica estadounidense, basada en el derecho consuetudinario, obliga a que las solicitudes se revisen de forma casuística y que lo que tenga más peso sea el juicio y las jurisprudencias. Rottman, Fariss y Poe $^{43}$ sintetizan las posibles vías en el proceso de las solicitudes de asilo en Estados Unidos en el siguiente esquema:

\section{ESQUEMA 1}

El proceso de asilo en EE.UU.

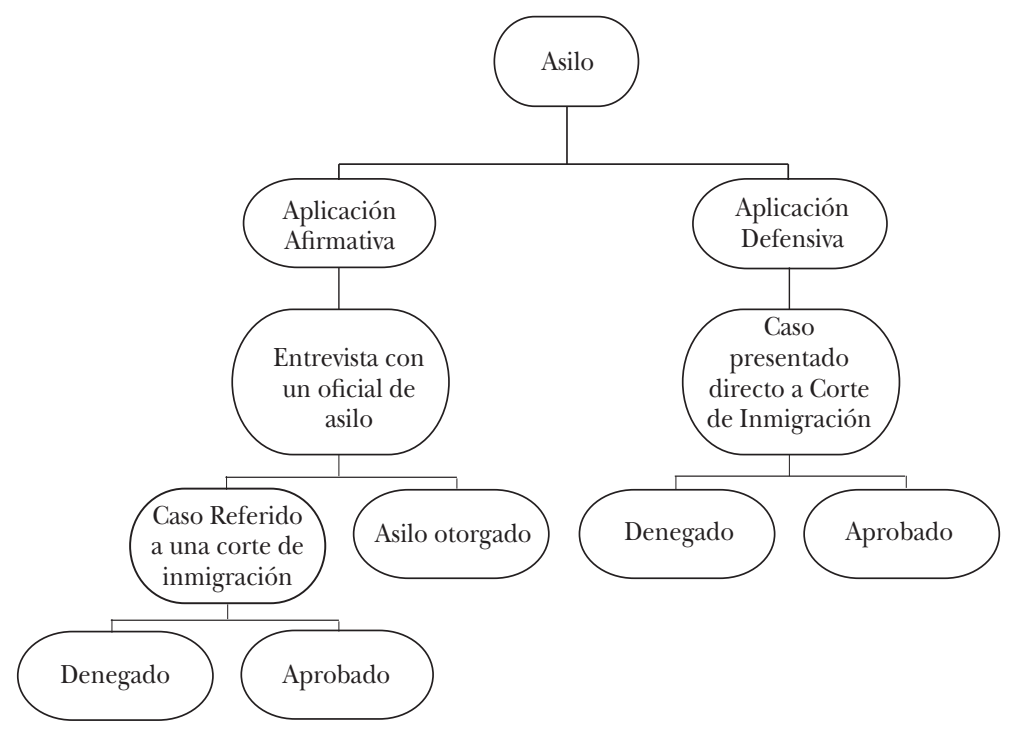

Fuente: Rottman et al., art. cit.

Al respecto, Ariadna Estévez ${ }^{44}$ enuncia varias problemáticas que considerar:

43 "The Path to Asylum in the US and the Determinants for Who Gets in and Why", International Migration Review, vol. 43, núm. 1, 2009, pp. 3-34.

44 "The Politics of Death and Asylum Discourse: Constituting Migration Biopolitics from the Periphery", Alternatives: Global, Local, Political, vol. 39, núm. 2, 2014, pp. 75-89. 
1. Hay un trato diferenciado de los solicitantes según su estatuto socioeconómico y género, lo cual para los jueces de inmigración es determinante según la supuesta tendencia a participar o a ser víctima del crimen organizado.

2. Por un lado, están aquellos que ingresan con una visa al país (asilo afirmativo), ${ }^{45}$ cuyas solicitudes de asilo son revisadas por la Oficina de ciudadanía y servicios de inmigración. En caso de ser denegadas se envían a un juez de inmigración de la Oficina ejecutiva de revisión de inmigración que forma parte del Departamento de Justicia.

3. Por otro, están aquellos que, al carecer de visa, inician un procedimiento de asilo defensivo. Son personas que llegan a un puesto fronterizo sin documentos y allí solicitan asilo. En estos casos, muchas veces las familias son separadas y enviadas a centros de detención donde permanecen hasta que el juez toma una decisión, la cual puede tomar hasta cinco años.

4. En el caso de asilo afirmativo, la negación se da bajo la explicación de que no se pudo probar persecución pasada y futura.

5. En el caso de asilo defensivo, se presenta un examen de miedo creíble y el proceso depende, casi siempre, de la veracidad que el juez le atribuya.

Demuestra todo esto que los marcos de referencia internacionales (Estatuto de Refugiados y su protocolo) y las leyes y procedimientos nacionales permiten ampliamente la arbitrariedad y la discrecionalidad, pues las cortes son administrativas, y se basan más en el análisis casuístico y el debido proceso, que en la garantía de los derechos humanos y las libertades fundamentales. Cabot, en su estudio arriba aludido, hace notar, por ejemplo, que

Una vez que un solicitante de asilo ha sido puesto en libertad o detenido, un oficial de asilo de USCIS realiza una entrevista de miedo creíble por lo general a través de videoconferencia. Ninguna de estas

${ }^{45}$ Se puede encontrar información detallada sobre el asunto en U. S. Citizenship and Immigration Services, "Asilo afirmativo", en https://www.uscis.gov/es/ programas-humanitarios/el-proceso-de-asilo-afirmativo 
dos entrevistas se registra textualmente. Ambos han sido editados o resumidos por el oficial que realizó la entrevista.

Los procedimientos en las cortes de apelación son largos, costosos y pocas veces exitosos.

En este sentido, destacan numerosas historias detalladas en los estudios de caso, ${ }^{46}$ medios de comunicación y documentales, ${ }^{47}$ entre los que se pueden diferenciar los que tienen mayor eco, como son los casos de policías, militares, activistas y sus familias. También hay historias de pequeños comerciantes o familias que son confundidas con narcotraficantes o extorsionados, que ante la violencia se dirigen a la frontera para solicitar asilo, sin saber que al llegar a la garita serán separados de sus familias y recluidos en centros de internamiento de extranjeros hasta por dos años mientras esperan audiencia. ${ }^{48}$ Los migrantes forzados huyen de las violaciones a los derechos humanos. Sin embargo, las vejaciones no terminan con la solicitud de asilo; los exámenes psicológicos a los que se enfrentan y los procedimientos largos e impredecibles, ponen a prueba su integridad física, mental y emocional. Incluso muchos de ellos permanecen en centros de detención fronterizos y al final muchas solicitudes son denegadas. ${ }^{49}$

Para prevenir la politización de los casos, los solicitantes se han valido del withholding of removal, medida precautoria que se basa en el artículo 33 de la Convención de 1951, según la cual se prohíbe retornar a un refugiado a un país donde su vida o su libertad esté amenazada. Esto implica un proceso paralelo y, según Uchimiya, sus requerimientos son aún más difíciles de probar, además de que no permite obtener la residencia a largo plazo, salir del país e incluso consiente la deportación a un tercer país que no implique riesgo (aunque esto sucede en circunstancias excepcionales). ${ }^{50}$

${ }^{46}$ Véanse los artículos citados de Uchimiya, Buchanan y Cabot.

47 Véanse Balderas, art. cit., y E. Urrutia, Buscando Asilo, documental de The Discovery Channel, 2010.

${ }^{48} \mathrm{~J}$. C. Martínez et al., art. cit.

${ }^{49}$ Boehm, art. cit.

${ }^{50}$ Uchimiya, art. cit. 
Los pocos casos que han tenido éxito en Estados Unidos son los de periodistas e informantes, entre los cuales, ocurrido en septiembre de 2010, el de José Luis Aguirre representa el primero. ${ }^{51}$ Buchanan asegura que otro caso común en las cortes estadounidenses es el de policías y militares que se rehúsan a cooperar con carteles del narcotráfico y al mismo tiempo reciben presión de autoridades corruptas. En estos casos se ha utilizado el grupo particular de "persecución por opinión política", por el cual

los agentes de policía pueden argumentar que en razón de su opinión política han decidido no asociarse o cooperar con el negocio de tráfico de drogas, y que han sido perseguidos [...]. Esto es un argumento convincente en vista de que el concepto de opinión política se define en términos generales y que algunos carteles de tráfico de drogas son efectivamente una fuerza política que continuamente tratan de infiltrarse en las instituciones gubernamentales. ${ }^{52}$

Este tipo de procesos obtiene mucha atención mediática por ser personas públicas, pero hay cientos de personas en pueblos recónditos que no pueden acceder a estos procedimientos y después de ser desplazados vuelven a ser amedrentados, porque los carteles se han extendido por todo el territorio nacional, y huyen a Estados Unidos como migrantes indocumentados. ${ }^{53}$ La ley difiere de la realidad, ya que el narcotráfico se reproduce y la violencia aumenta, mientras que los marcos jurídicos existentes parecen obsoletos al no entender los desafíos actuales del refugio y el asilo. Además, el derecho internacional sobre refugiados corresponde sólo a marcos de referencia, sin carácter vinculante y cuya aplicación depende de la "buena voluntad" de los estados. La flexibilización de dicha legislación, el hecho de ampliar o precisar la figura de refugiado, sería un avance importante. Sin embargo, eso no garantiza que los jueces sean más ecuánimes y objetivos en

${ }^{51}$ Boehm, art. cit.

${ }^{52}$ Buchanan, art. cit.

${ }^{53}$ Véase L. H. Atuesta y D. Paredes, "Do Mexicans flee from violence? The effects of drug-related violence on migration decisions in Mexico", Journal of Ethnic and Migration Studies, vol. 42, núm. 3, 2016, pp. 480-502. 
sus decisiones y tampoco implica que los gobiernos amplíen sus capacidades administrativas para atender todos los casos que rebasarían las posibilidades reales de admisión de los países otorgantes de asilo.

En general, el asilo y el refugio, aunque medidas de protección necesarias, sólo son acciones paliativas para las demandas de poblaciones vulnerables que ven afectados sus derechos por circunstancias ajenas a su identidad nacional, cultural o étnica; no son soluciones reales y de fondo a las problemáticas sociales, políticas y culturales que genera el mercado de narcóticos ilícitos en el sistema capitalista. En este sentido, ¿quiénes son los responsables de los desplazados internos e internacionales? ¿Los "narcos", que en un marco de ilegalidad y persecución gubernamental satisfacen una demanda real, pero censurada? ¿Los gobiernos que protegen la moralidad del capitalismo combatiendo el tráfico de drogas, pero que han consentido el narcotráfico desde sus orígenes y participan en las cadenas de corrupción e impunidad, generando más violencia a partir de este doble discurso? ¿El consumidor de drogas final que se puede dibujar mediante diversos perfiles de clase social, valores, estrato, educación?

\section{LA CORRESPONSABILIDAd ENTRE ESTADOS Unidos y MÉXico POR LOS REFUGIADOS DEL NARCOTRÁFICO}

En este apartado se puntualiza cómo el narcotráfico es parte de una dinámica oferta-demanda entre México y Estados Unidos, en la cual una visión prohibicionista del consumo de sustancias ilícitas ha generado niveles altos de violencia del lado productor. Si bien la violencia se ha enfrentado con estrategias de seguridad basadas en la asistencia y la cooperación bilateral en el rubro, en el caso de las problemáticas relacionadas con derechos humanos y costos sociales hay poco sentido de corresponsabilidad en la región.

La movilidad forzada interna e internacional generada por los procesos en torno al narcotráfico se ha disimulado. Albuja y Rubio exponen las siguientes razones en su estudio antes citado. Primero, los medios de comunicación han brindado mayor atención a otros 
abusos y atrocidades cometidos tanto por los carteles de la droga, como por las fuerzas de seguridad pública (ejército, marina y policía federal). Segundo, las instituciones del Estado minimizan e ignoran el fenómeno para evitar la desacreditación de las estrategias contra el narcotráfico y las percepciones de seguridad pública. En el caso particular de los desplazados internos destaca además el vacío conceptual, legal e institucional del país.

En este sentido, cabe preguntarse: ¿Estados Unidos es responsable ante su problema de consumo de drogas por la violencia y la migración forzada en países como México? Ambos países han insistido en los discursos y en las estrategias que es necesario trabajar de manera conjunta. Con todo, en el marco de las complejas y asimétricas relaciones en América del Norte destaca el narcotráfico. Estados Unidos desde los albores de su hegemonía se ha caracterizado por determinar el paradigma de seguridad internacional, pero el narcotráfico ha sido siempre un tabú para el gobierno y la sociedad estadounidenses.

Así pues, encontramos que el $90 \%$ de las armas ilegales en México viene de Estados Unidos ${ }^{54}$ y que éste es el mayor consumidor del mundo en términos absolutos. Pese a que el consumo de drogas está prohibido por la Ley de Sustancias Controladas (1970), ${ }^{55}$ las estadísticas reflejan que en 2007 y 2011 se presentó un incremento de 4 millones de personas (22.5 millones en total) que consumieron alguna droga ilícita. ${ }^{56}$ Éste es un mercado transnacional en que la demanda de drogas ilícitas se cubre por cadenas productivas internacionales donde la violencia se genera en el proceso de trasie-

${ }^{54}$ Cabot, art. cit.

${ }^{55}$ De todas las sustancias ilícitas que se consumen en Estados Unidos, sólo la marihuana, además de ser la más consumida, se ha despenalizado para su uso recreativo en Washington, Colorado, Distrito de Columbia y en municipios de Oregon, Alaska, Michigan, Nuevo México, Filadelfia, Pensilvania, Maine y Portland, y para su uso medicinal, en California. Véase R. Room, "Legalizing a Market for Cannabis for Pleasure: Colorado, Washington, Uruguay and beyond”, Addiction, vol. 109, núm. 3, 2014, pp. 345-351.

${ }^{56}$ U. S. National Institute on Drug Abuse, 2011, en https://www.drugabuse. gov/news-events / news-releases/2011/12/national-institute-drug-abuse-to-announce-results-2011-monitoring-future-survey 
go ilegal de fronteras. ${ }^{57}$ Hasta hace algunos años (hoy la violencia ha pasado la frontera), cuando la droga llegaba a Estados Unidos, generaba solamente problemas de salud pública, cuyo costo social se reducía a los programas de rehabilitación, recuperación y reintegración, mientras que otros problemas sociales relacionados directamente con la violencia generada por el consumo ilícito se quedan en el país productor.

Por lo demás, uno de los cambios más significativos tras el 11/S para el proceso de asilo proviene de la Ley Patriota, pues la mínima presumible relación con el terrorismo (con todo y lo ambigua que es esta definición en el documento que incluye incluso el narcotráfico) implica la denegación absoluta del proceso. ${ }^{58}$ Aún más, las opiniones sobre los solicitantes de asilo en Estados Unidos están divididas. Cabot, por ejemplo, en su trabajo anteriormente citado, explica que

los políticos y los medios de comunicación se han pronunciado en contra de los solicitantes de asilo en México, descalificándolos como delincuentes y sus reclamaciones fraudulentas. En respuesta a un artículo de Fox News en agosto de 2013 alegando que los solicitantes de asilo en México ponen en riesgo el sistema de inmigración de Estados Unidos, el senador estadounidense Jeff Sessions (R-AL) declaró que la capacidad de buscar asilo en la frontera estaba destruyendo la vigilancia fronteriza.

El paradigma de seguridad, según se observa, sigue privando en las discusiones sobre movilidad humana. En su análisis sobre las determinantes que condicionan el otorgamiento o la denegación de asilo en Estados Unidos, ya citado arriba, Rottman, Fariss y Poe presentan, entre muchas otras, las siguientes conclusiones:

1. A mayor importancia del país de origen para los intereses de seguridad de Estados Unidos (medida por la recepción de ayuda militar) es menos probable que se apruebe la solicitud.

${ }^{57}$ Véanse las obras citadas de Valencia, Buscaglia y Astorga.

${ }^{58}$ Rottman et al., art. cit. 
2. Entre más importante sea el país de origen para los intereses económicos de Estados Unidos (medidos en intercambio comercial) es menos probable la aprobación.

3. Solicitantes de asilo que provienen de un país que envía densos flujos de migrantes indocumentados son considerados menos aptos para obtener asilo.

En suma, la inaplicabilidad de las normas internacionales, lo casuístico e impredecible de los procesos, obstaculizan la obtención de protección internacional a las víctimas de la violencia por narcotráfico. México es el país con más migrantes en Estados Unidos; pertenece a un tratado comercial en Norteamérica; es el segundo destino de exportaciones y el tercero de importaciones, y hasta su bloqueo en 2015 existe la Iniciativa Mérida que incluye fondos para el combate al narcotráfico. ${ }^{59}$ En este sentido, las posibilidades de las víctimas de violencia por el narcotráfico son aún más limitadas.

Surge un segundo cuestionamiento ante el aumento de las solicitudes y las evidencias del clima de violencia: ¿debe flexibilizar Estados Unidos las leyes y procedimientos para acoger a víctimas de la violencia por la producción y tráfico de psicotrópicos ilícitos? La respuesta no es simple y se deberían tomar en cuenta varios supuestos.

En primer lugar, debería haber mayor voluntad política para asumir responsabilidad por parte de Estados Unidos en las cadenas transnacionales de producción y distribución de drogas y la violencia que causan. Por ejemplo, sólo el $15 \%$ del presupuesto de la Iniciativa Mérida está relacionado con los derechos humanos. ${ }^{60}$ Además, Estados Unidos debería exigir que sus contribuciones al combate del narcotráfico (Iniciativa Mérida) incluyan programas de prevención social, transparencia y vigilancia de los derechos humanos, ${ }^{61}$ es decir evitar combatir la violencia con más violencia. Otra posibilidad bastante debatida y con argumentos en pro y en

${ }^{59}$ Véase R. Benítez-Manaut (ed.), Crimen organizado e Iniciativa Mérida en las relaciones México-Estados Unidos, México, Casede, 2010.

${ }^{60}$ Cabot, art. cit.

${ }^{61}$ Benítez-Manaut, ed. cit. 
contra, a su vez, sería intercambiar la prohibición de drogas por su regulación.

En segunda instancia, la migración forzada se concibe como una alternativa última para individuos y familias que ven vulnerados sus derechos y libertades fundamentales. Se trata de situaciones finales donde hay que elegir entre la vida y dejar atrás todo lo que conocen. En este sentido, debería haber mecanismos, programas y procedimientos de protección más efectivos por organismos desconcentrados (para evitar corrupción e impunidad) a los que estas familias e individuos puedan recurrir para no tener que alcanzar la frontera y cruzarla de forma ilegal. Estas medidas son a largo plazo, pero hay que tomar en cuenta que el problema existe y que muchos mexicanos tienen que dejar su cultura, su patrimonio, su trabajo, sus amigos y familia por el miedo, la persecución, el secuestro, la extorsión, la tortura, la amenaza y la muerte de sus seres queridos. Además de su diáspora mixta, México tiene el problema de los migrantes y refugiados (particularmente los menores no acompañados) provenientes de Centroamérica, flujo que Estados Unidos ha presionado para que se detenga antes de alcanzar su frontera. 62

En este sentido, es normal que las solicitudes de asilo en Estados Unidos aumenten, pero también tiene fundamento el rechazo basado en las siguientes consideraciones:

1. La legislación internacional tiene una definición ambigua e imprecisa que no incorpora los nuevos refugiados (incluyendo a los ambientales, minorías sexuales y víctimas de violencia).

2. En caso de una revisión a conciencia de los casos y flexibilización de los parámetros, dada la situación de violencia en México, serían más las personas que entrarían en el caso de asilo que la capacidad real de Estados Unidos (presupuesto, logística e integración) para acoger a estas personas.

3. Hay redes que promueven la construcción de casos "falsos" o que lucran con los procesos de asilo, deslegitimando las situaciones reales.

${ }^{62}$ E. G. Ferris, "Mexico and the Central American Refugees." Journal of Interamerican Studies and World Affairs, vol. 26, núm. 3, 2016, pp. 357-384. 
La migración forzada conlleva múltiples procesos: los judiciales, el establecimiento de centros de atención y detención, el subsecuente proceso de integración, entre otras problemáticas propias de la acogida: "El asilo representa un caso crítico para el debate normas versus intereses, debido a que la protección de las personas vulnerables es un proyecto humanitario por excelencia, pero pueden tener altos costos estratégicos". ${ }^{63}$ En este sentido, el punto importante no es sólo disentir sobre la responsabilidad o la flexibilización normativa de Estados Unidos, sino tomar en cuenta que el país no podría gestionar ni económica ni administrativamente el asilo de todas las víctimas de la violencia por el narcotráfico, pues, como se puede percibir en la actualidad, los jueces están saturados y hay una reticencia a aceptar asilo por narcotráfico.

Otra cuestión de diferente naturaleza que debería considerarse es el hecho de que las redes de narcotráfico son transnacionales y, por tanto, la violencia también se empieza a exportar a Estados Unidos. Cada vez son más comunes las peleas, homicidios, balaceras, por luchas territoriales en barrios marginados en Estados Unidos, particularmente en vecindarios de latinos que es donde por lógica se establecerían los asilados mexicanos, es decir cruzar la frontera ya tampoco será una alternativa para los perseguidos por la violencia del narcotráfico.

\section{Conclusiones}

En este texto, se analizaron de forma holística varias variables que tomar en cuenta en el momento de examinar el proceso de migrantes forzados por la violencia causada por el narcotráfico. El narcotráfico no puede calificarse a la luz de juicios maniqueos, porque sólo es un subsistema económico que tiene un mercado global y que se refuerza por sistemas socio-culturales que promueven el consumo de sustancias psicotrópicas lícitas e ilícitas. Estamos frente a una guerra por rutas y mercados, en que estas actividades vio-

${ }^{63}$ Rosenblum, art. cit., p. 680. 
lentan los derechos y libertades fundamentales y generan números aún desconocidos de desplazados y migrantes forzados nacionales e internacionales.

Los migrantes forzados, refugiados o asilados, independientemente de la connotación académica, incluyente o legalista desde la cual se quiera aproximarse a la problemática, se han diversificado y complicado en sus perfiles. En este sentido, las definiciones clásicas de "grupo social particular", las críticas a los procesos para probar el "temor fundado" o la persecución, así como los "ejecutores" de distinta naturaleza a los tradicionalmente reconocidos, obligan a replantear los marcos de referencia existentes, así como los procesos normativos, administrativos y también la ética en las relaciones bilaterales.

En cuanto al marco normativo internacional vigente en Norteamérica, encontramos que el Derecho Internacional sobre migración forzada contenido principalmente en el Estatuto de los Refugiados y su protocolo es ambiguo e insuficiente, pues los solicitantes se han tenido que valer de otras legislaciones como la Convención contra la tortura y la Convención para la protección de todas las personas contra la desaparición forzada. Basados sólo en la buena voluntad de los estados, estos instrumentos merecen una revisión urgente y profunda que les permita servir como marcos de referencia acordes con las problemáticas actuales.

El asilo encarna un complejo debate entre normas de derechos humanos y libertades fundamentales e intereses políticos. Es un proyecto humanista por excelencia de las naciones, pero pocas veces hay condiciones para gestionar estos costos sociales de la violencia. Se ha debatido ampliamente la asimetría y complejidad que caracterizan las relaciones bilaterales entre México y Estados Unidos, pero es un hecho que lo que sucede de un lado de la frontera encuentra su origen, causa, cauce y efectos en el otro. En este sentido, el incremento de solicitudes de asilo por la violencia derivada del narcotráfico coincide, por un lado, con el incremento de consumidores, y la prohibición y la guerra contra el narcotráfico, por el otro. En este proceso, las víctimas se cuentan entre los efectos colaterales y, por tanto, los refugiados 
por narcotráfico seguirán generándose e involucrando a los dos países.

Mientras no se encuentren soluciones de largo plazo a la violencia generada por el narcotráfico, debe evitarse que los asilados sufran de una doble victimización a causa de los largos procesos judiciales, de la reclusión en centros de detención por periodos prolongados, de la separación de familias, del retorno por denegación y en caso de aprobación buscar una integración positiva al país de acogida. Esto también promueve que las solicitudes de asilo se revisen de forma casuística y discrecional. El reconocimiento de una crisis por migración forzada será entonces una cuestión politizada.

Es evidente que no son las personas las que causan la migración forzada. Antes bien, el miedo y la persecución las obligan a desplazarse e ingresar a otro país, lo cual conlleva varios procesos: de justicia (jueces, abogados y personal administrativo que se encarguen del caso), centros de detención (personal de salud, psicólogos, alimentos y asistencia en general), de integración (vivienda, trabajo, seguridad social), entre otras problemáticas propias de la acogida. No basta con voluntad política y marcos normativos vanguardistas. La otra realidad es que no hay capacidad estructural en los gobiernos para gestionar las demandas de estos refugiados.

De la misma manera en que no hay una solución simple y duradera al complejo problema del narcotráfico, tampoco hay cura para sus efectos sociales y humanos. Lo cierto es que el escenario deseable es que el fenómeno de migración forzada por violencia generada por el trasiego de narcóticos entre México y Estados Unidos no se masifique; el escenario realista es que hay numerosas solicitudes y, por tanto, crece la tasa de rechazo y, ante el nivel de riesgo, las víctimas se mezclan con los flujos migratorios. Los argumentos formales de Estados Unidos para no otorgar asilo político están justificados procedimentalmente, pero si se toma en cuenta la demanda de drogas ilícitas y el contrabando de armas en el sentido contrario, la ética obliga a repensar las estrategias para gestionar la movilidad humana en la región, con especial atención a los casos de migración forzada. 


\section{BibliogRAFía}

ACNUR, Convención sobre el Estatuto de los Refugiados, adoptada en Ginebra, Suiza, el 28 de julio de 1951, por la Conferencia de plenipotenciarios, en http://www.acnur.org/fileadmin/scripts/doc.php?file=filea dmin/Documentos/BDL/2001/0005

— Manual de procedimientos y criterios para determinar la condición de refugiado en virtud de La Convención de 1951 y el Protocolo de 1967 sobre el Estatuto de Los Refugiados, en http://www.acnur.org/t3/fileadmin/ Documentos/BDL/2011/7575.pdf

— Estadísticas de Población. Base de datos en línea, en http:// popstats.unhcr.org/en/time_series

Albuja, Sebastián, "Criminal violence and displacement in Mexico", Forced Migration Review, núm. 45, 2014, pp. 28-31.

y Laura Rubio Díaz-Leal, "Los olvidados de la guerra contra el narcotráfico en México. Los desplazados internos”, Foreign affairs: Latinoamérica, vol. 11, núm. 4, 2014, pp. 23-31.

Astorga, Luis, Drogas sin fronteras, México, Debolsillo, 2015.

Atuesta, Laura H. y Dusan Paredes, "Do Mexicans flee from violence? The effects of drug-related violence on migration decisions in Mexico", Journal of Ethnic and Migration Studies, vol. 42, núm. 3, 2016, pp. 480502, doi:10.1080/1369183X.2015.1079122.

Balderas, Óscar, "El hotel donde vive un pueblo entero desplazado por el narcotráfico", Vice News, 15 de marzo de 2016.

Barry-Murphy, Emily y Max Stephenson Jr., "Recognizing and Confronting State Subjectivity in Asylum Adjudications”, Refuge, vol. 31, núm. 2, 2015, pp. 1-17.

Bauman, Zygmunt, Vidas desperdiciadas. La modernidad y sus parias, Barcelona, Paidós, 2005.

Benítez-Manaut, Raúl (ed.), Crimen organizado e Iniciativa Mérida en las relaciones México-Estados Unidos, México, Casede, 2010.

Bezares Buenrostro, Héctor, Análisis sobre los fundamentos políticos de las políticas antinarcóticos en los Estados Unidos, tesis, México, Universidad Nacional Autónoma de México, 2007.

Boehm, Deborah A., "US-Mexico Mixed Migration in an Age of Deportation: An Inquiry into the Transnational Circulation of Violence", 
Refugee Survey Quarterly, vol. 30, núm. 1, 2011, pp. 1-21, doi:10.1093/ $\mathrm{rsq} / \mathrm{hdq} 042$.

Buchanan, Holly, "Fleeing the Drug War Next Door: Drug-Related Violence as a Basis for Refugee Protection for Mexican Asylum-Seekers", Merkourios, vol. 27, núm. 72, 2011, pp. 28-60, en http://www.merkourios.org/index.php/mj/article/view/21

Buscaglia, Edgardo, Vacíos de poder en México. El camino de México hacia la seguridad humana, pról. de Carmen Aristegui, México, Debate, 2013.

Cabot, J. Anna, "Problems Faced by Mexican Asylum Seekers in the United States", Journal on Migration and Human Security, vol. 2, núm. 4, 2014, pp. 361-377.

Campos, Sara y Joan Friedland, "Mexican and Central American Asylum and Credible Fear Claims: Background and Context", American Immigration Council, 21 de mayo de 2014.

Cobo, Salvador y Pilar Fuerte, "Refugiados en México. Perfiles sociodemográficos e integración social", ACNUR México, en http://www.acnur. org/t3/fileadmin/Documentos/Publicaciones/2013/9167.pdf

Durin, Séverine, "Los que la guerra desplazó: familias del noreste de México en el exilio”, Desacatos, núm. 38, enero-abril 2012, pp. 29-42.

Estévez, Ariadna, "Asilo y derechos humanos en Estados Unidos y Canadá. Cuestionamientos a Giorgio Agamben”, Norteamérica, vol. 7, núm. 1, 2012, pp. 183-206.

, "The Politics of Death and Asylum Discourse: Constituting Migration Biopolitics from the Periphery", Alternatives: Global, Local, Political, vol. 39, núm. 2, 2014, pp. 75-89.

Ferris, Elizabeth G., "Mexico and the Central American Refugees." Journal of Interamerican Studies and World Affairs, vol. 26, núm. 3, 2016, pp. 357-384.

IDMC: Internal Displacement Monitoring Centre, "Global Report on Internal Displacement”, 2016, en http://www.internal-displacement. org/assets / publications /2016/2016-global-report-internal-displacement-IDMC.pdf

Keith, Linda Camp y Jennifer S. Holmes, "A Rare Examination of Typically Unobservable Factors in US Asylum Decisions", Journal of Refugee Studies, vol. 22, núm. 2, 2009, pp. 224-241, doi:10.1093/jrs/fep008.

Martínez, Jesús C., Ramón Alvarado y Nicole Chávez, "Unrelenting Violence and Lawlessness Forces Thousands of Middle-Class Mexicans to 
Relocate Seeking Safety in the U.S. and in More Peaceful Regions in México", Mexodus, 31 de junio de 2011.

Monsiváis, Carlos, "El narcotráfico y sus legiones", en C. Monsiváis et al., Viento rojo. Diez historias del narco en México, México, Plaza y Janés, 2004, pp. 7-44.

Morales, Maria, Oscar Morales, Angelica Menchaca y Adam Sebastian, "The Mexican Drug War and the Consequent Population Exodus: Transnational Movement at the U.S.-Mexican Border”, Societies, vol. 3, núm. 1, 2013, pp. 80-103, doi:10.3390/soc3010080.

Reuter, Peter, "On the Multiple Sources of Violence in Drug Markets", Criminology Ẽ Public Policy, vol. 15, núm. 3, 2016, pp. 877-883, doi:10.1111/1745-9133.12224.

Room, Robin, "Legalizing a Market for Cannabis for Pleasure: Colorado, Washington, Uruguay and beyond", Addiction, vol. 109, núm. 3, 2014, pp. 345-351, doi:10.1111/add.12355.

Rosenblum, Marc R., "Norms and Interests in US Asylum Enforcement", Journal of Peace Research, vol. 41, núm. 6, 2016, pp. 677-697.

Rottman, Andy J., Christopher J. Fariss y Steven C. Poe, "The Path to Asylum in the US and the Determinants for Who Gets in and Why", International Migration Review, vol. 43, núm. 1, 2009, pp. 3-34, doi:10.1111/ j.1747-7379.2008.01145.x.

The Fund for Peace, "Fragile States Index", 2016, en http://fsi.fundforpeace.org/

Uchimiya, Diane, "Falling Through the Cracks: Gang Victims As Casualties in Current Asylum Jurisprudence”, Berkeley La Raza Law Journal, vol. 23, 2013, pp. 109-162, doi:10.15779/Z389H4G.

Urrutia, Eduardo, Buscando Asilo, documental de The Discovery Channel, 2010.

U. S. Citizenship and Immigration Services, "Asilo afirmativo”, en https:// www.uscis.gov/es/programas-humanitarios/el-proceso-de-asilo-afirmativo

U. S. Department of Justice, "Asylum Statistics", 2016, en https://www. justice.gov/eoir/file/asylum-statistics/download

U. S. National Institute on Drug Abuse, 2011, en https://www.drugabuse. gov/news-events / news-releases /2011/12/national-institute-drugabuse-to-announce-results-2011-monitoring-future-survey

Valencia, Sayak, Capitalismo Gore, Barcelona, Melusina, 2010. 
Wallerstein, Immanuel, Análisis de sistemas-mundo. Una introducción, México, Siglo XXI, 2005.

— , "A world-system perspective on the social sciences", en The capitalist world-economy, Cambridge, University Press, 1979 (reimpresión de 1997).

Žižek, Slavoj, "Sobre la violencia. Seis reflexiones marginales", trad. de A. J. Antón Fernández, Buenos Aires, Paidós, 2009.

Zolberg, Aristide R., Astri Suhrke y Sergio Aguayo, Escape from Violence: Conflict and the Refugee Crisis in the Developing World, Oxford, University Press, 1989. 